\title{
The Research on Bitcoin transaction fees based on Var model
}

\author{
Zheng Huang ${ }^{1}$, Shuangcheng $\mathrm{Li}^{1}$, Yunying Lu ${ }^{1}$, and Qing Wang ${ }^{1+}$ \\ ${ }^{1}$ Beijing University of Posts and Telecommunications
}

\begin{abstract}
Bitcoin transaction fee is an important kind of transaction costs that can be observed. In this paper, we address that the long-term effects of the demand are greater than that of the supply through empirical analyses of the influence degree of computational power, the number of transactions and the price of bitcoin. Based on the theory of supply and demand, there is a trend upward for bitcoin transaction fee in the future.
\end{abstract}

Keywords: bitcoin, transaction fees, cost, VAR

\section{Introduction}

Transaction fees are the explicit transaction cost of bitcoin. The transaction cost of bitcoin is very low due to its design of the peer-to-peer and its transaction avoiding financial institutions involved [1]. Prior to 2008, there was almost no transaction fee for bitcoin transactions, and then each transaction charges a corresponding transaction fee. In this paper, after studying the impact of three factors on transaction fees, a long-term prediction has been made that transaction costs will have a higher trend according to the economic equilibrium theory.

\section{Literature review}

The concept of transaction costs was put forward by Ronald H. Coase in "The nature of the firm" published in 1937, but in fact he emphasized the decisive role played by the transaction cost in the allocation of resources, which limits the application of transaction cost theory [2] .Williamson (1985) further developed the concept of transaction cost [3] . He believed that the transaction cost was "the cost of the economic system or the cost of operation". In general, the transaction cost can be divided into three categories including search and information costs, bargaining costs and policing and enforcement costs execution cost [4].

According to whether it can be directly observed in the market, transaction costs can be divided into explicit transaction costs and implicit transaction costs. The explicit transaction cost includes fees, taxes and so on [5], which can be calculated directly by the market data. In the bitcoin transaction, a fixed handling fee and a user's overpayment fee are both involved.

Many researches have been made on the miner incentive mechanism which is highly related to bitcoin transaction fees. Kroll (2013) proposes that there is a Nash equilibrium between incentive mechanisms for the transaction costs of miners [6]. Houy(2014) suggests that if bitcoin users can pay high enough fees to make their transactions to be process faster and put forward some directions for bitcoin transaction costs and algorithmic optimization in the future by game theory analysis between the miners and the transaction fee[7] .

The study of Bitcoin transaction costs, especially empirical analysis, is still scarce, so we will innovate from this perspective, quantify the explicit costs and analyze the impact of various factors on it. This provides the possibility of further forecasting on the tendency of transaction cost for us in the future.

\footnotetext{
+ Corresponding author. Tel.: +86 18401695692

E-mail address: 362484006@qq.com
} 


\section{EMPIRICAL Analysis}

\subsection{Reasons for selecting variables}

According to the traditional economic theory, the price depends on the supply and demand and there is a long-term equilibrium relationship between supply, demand and price. The supply of Bitcoin is theoretically exogenously given, and is derived from the programmed algorithm which is directly related to the computational power of Bitcoin. $\mathrm{Ms}=\mathrm{B}+\mathrm{f}(\mathrm{X})$. (B is the bit currency in circulation and $\mathrm{f}(\mathrm{X})$ is a function of the computational power.) According to the Fisher equation $\mathrm{Md}=\mathrm{PY} / \mathrm{V}$, when they are at the equilibrium $\mathrm{B}+$ $\mathrm{f}(\mathrm{X})=\mathrm{PY} / \mathrm{V}$ (P denotes the price level depending on the goods and services, Y denotes the economic scale of the bitcoin and $\mathrm{V}$ denotes the bitcion circulation rate (measuring the frequency at which a unit bit of money is used to purchase goods and services)), we get $\mathrm{B}=\mathrm{PY} / \mathrm{V}-\mathrm{f}(\mathrm{X})$, which shows that there is a negative correlation between computational power $\mathrm{X}$ and bitcoin stock which is positively correlated with price level and economic scale. There is a close relationship between the amount of bitcoin transactions and its transaction fees.

Therefore, in this empirical analysis, transaction fees have been selected as the dependent variable, and computational power, price and transaction quantity as the independent variables. Then we study that how the latter three factors affect the transaction fee through model establishment, co-integration test and error correction.

\subsection{Data collection and stastistical methods}

\section{1) Data description}

The data of this empirical analysis are mainly obtained from blockchain.info.

The empirical analysis of the sample interval for bitcoin has developed more mature for nearly two years, 2013 Data for the period from 1 January to 24 December 2016.

Consider the variables as follows: Independent variables: computational power which is also expressed as a hash rate, the quantity of bitcoin transactions per day, bitcoin price which is expressed in the average dollar price per day of the bitcoin.

Dependent variable: bitcoin transaction fee which is represented by the proportion of bitcoin used for transaction costs in each transaction. All variables take logarithms to eliminate the possibility of heteroscedasticity, and logarithmic forms can also reflect long-term elasticity.

Table I: Variable Code and its Meaning

\begin{tabular}{ll}
\hline Variable code & Variable meaning \\
\hline Ic & $\begin{array}{l}\text { The proportion of bitcoin used for transaction costs in each transaction takes the } \\
\text { logarithm. }\end{array}$ \\
\hline $\mathbf{l h r}$ & Hash rate takes the logarithm. \\
\hline $\mathbf{l t v}$ & The quantity of bitcoin transactions per day takesthe logarithm. \\
\hline $\mathbf{l m p}$ & The average dollar price per day of the bitcoin takes the logarithm. \\
\hline
\end{tabular}

2) Stability test

It is necessary to make sure whether the variables are single integers before examining whether a set of data exists in a co-integration relationship. If not, determine the single order of the variables. This empirical analysis uses ADF method to test the stability of the variables and the results are shown in TABLE II.

Table II: The Stability of Variables

\begin{tabular}{lllll}
\hline Variable & Inspection type $(\mathbf{C , T , K})$ & $\mathbf{A D F}$ & $\mathbf{1 \%}$ critical value & Conclusion \\
\hline $\mathbf{l c}$ & $(\mathrm{C}, \mathrm{N}, 35)$ & -1.80 & -3.44 & Non-stationary \\
\hline $\boldsymbol{\Delta \mathbf { l c }}$ & $(\mathrm{N}, \mathrm{N}, 34)$ & -7.89 & -2.57 & steady \\
\hline $\mathbf{l h r}$ & $(\mathrm{C}, \mathrm{N}, 13)$ & -1.06 & -3.44 & Non-stationary \\
\hline $\mathbf{\Delta} \mathbf{l h r}$ & $(\mathrm{N}, \mathrm{N}, 7)$ & -16.50 & -2.57 & steady \\
\hline $\mathbf{l t v}$ & $(\mathrm{C}, \mathrm{N}, 48)$ & -2.53 & -3.44 & Non-stationary \\
\hline $\boldsymbol{\Delta \mathbf { l t v }}$ & $(\mathrm{N}, \mathrm{N}, 47)$ & -5.98 & -2.57 & steady \\
\hline $\mathbf{l m p}$ & $(\mathrm{C}, \mathrm{N}, 2)$ & -0.45 & -3.44 & Non-stationary \\
\hline $\boldsymbol{\Delta \mathbf { l m p }}$ & $(\mathrm{N}, \mathrm{N}, 1)$ & -22.7 & -2.57 & steady \\
\hline
\end{tabular}


Note: In the test type, $\mathrm{C}$ and $\mathrm{T}$ indicate that the test equation has an intercept term and a trend term ( $\mathrm{N}$ for no corresponding term), and $\mathrm{K}$ is the optimal lag order determined by the AIC criterion.

From the unit root test results can be seen, lc $\sim$ I (1), lhr $\sim$ I (1), ltv I (1), lmp $\sim$ I (1). It shows that there may be some kind of stable and long-term relationship between them.

\subsection{Co-integration test}

\section{1) Determination of co integration order}

To establish an unconstrained VAR model with various lagging orders, we can get that the minimum AIC is 9 order, and the minimum value from SC is 3 order. From the practical point of view, if the focus is to investigate whether there is co-integration vector VAR model, the lag should be as large as possible so as to eliminating the error in the auto-correlation. So the VAR model adopts the maximum order of lag of 9 orders.

\section{2) Johansen Co-integration test}

The order of the Johansen co-integration test is 8th order, and the co-integration test with no trend is selected. Both the maximum eigenvalue test and the results of trace test show that there are two co-integration equations at the $5 \%$ significance level, indicating that there is a stable long-run equilibrium relationship among the variables.

Table IIII: Conclusions of Johansen Co-Integration Test

\begin{tabular}{|c|c|c|c|c|}
\hline $\begin{array}{c}\text { Hypothesized No. } \\
\text { of CE(s) }\end{array}$ & $\begin{array}{c}\text { Trace } \\
\text { statistic }\end{array}$ & $\begin{array}{c}5 \% \text { critical } \\
\text { value }\end{array}$ & $\begin{array}{c}\text { Max-eigen } \\
\text { statistic }\end{array}$ & $\begin{array}{l}5 \% \text { critical } \\
\text { value }\end{array}$ \\
\hline None * & 80.60 & 47.856 & 37.35 & 27.584 \\
\hline At most one * & 43.25 & 29.797 & 27.95 & 21.132 \\
\hline At most two * & 15.30 & 15.495 & 15.16 & 14.265 \\
\hline At most three & 0.14 & 3.841 & 0.14 & 3.841 \\
\hline
\end{tabular}

The regularized co integration equation is:

$$
\begin{gathered}
\mathrm{lc}_{t}=4.04 \times \operatorname{lmp}_{t}+4.35 \times \mathrm{ltv}_{t}-3.0 \times \mathrm{lhr}_{t}-37.4+\varepsilon_{t} \\
(-4.47) \quad(-4.96)
\end{gathered}
$$

Where ECM is the error correction term, and the t-statistic of each coefficient is marked in parentheses. It can be seen from the above equation that all the coefficients are significant at the $1 \%$ significance level.

From the positive and negative view of the coefficient of the variables, the transaction quantity is positively related to the transaction fee, while the computational power and the transaction fee are negatively correlated. The computational power and the transaction quantity are equal to the supply and demand quantity respectively, and the transaction cost is equal to the transaction price. This relationship is consistent with the theory of supply and demand in economic theory. Equilibrium point $\mathrm{E}$ is the transaction fee and the number of transactions determined by the market while the external economic environment is constant.

From the size of the variable coefficient, the transaction volume elasticity of the transaction fee is $4.35 \%$ which is greater than the hash rate of the transaction fee elasticity of 3.0\%, which suggests that the long-term impact of demand on transaction costs is greater than that of supply on transaction fees. In the future, the change of external economic policy may lead to the shift of the demand curve to the right, while the supply will be constrained and the speed of the right curve will slow down.

The market price of bitcoin is also positively related to transaction costs. Because the number of transactions of bitcoin unchanged, in this case, the higher market price leads to the higher value of bitcoin transaction. Therefore, the transaction fee could be higher. Bitcoin price elasticity of the transaction fee is $4.04 \%$ which is the greatest influence factor that cannot be ignored. 


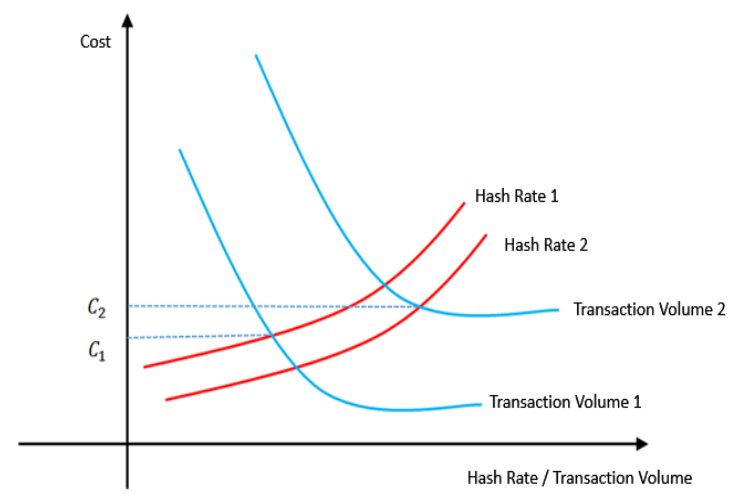

Fig.1: Supply curve and demand curve

\subsection{Error correction model}

Co-integration analysis proves that there exists a long-term equilibrium relationship among the variables, but it can also be unbalanced in a short time. The short-term disequilibrium dynamic structure can be expressed by the error correction model. Since each variable is an I (1) sequence, and there is a co-integration relationship. It is inevitable to establish the error correction model based on the Granger theorem.

Table IV: Lagged Variable during Different Lag Period

\begin{tabular}{l|llll}
\hline \multirow{2}{*}{ Number of lag periods } & \multicolumn{4}{l}{ Lagged variable } \\
\cline { 2 - 5 } & $\begin{array}{l}\mathrm{D}(\mathrm{LC}(-\mathrm{T})) \\
\alpha_{\mathrm{T}}\end{array}$ & $\begin{array}{c}\mathrm{D}(\mathrm{LMP}(-\mathrm{T}) \\
\beta_{\mathrm{T}}\end{array}$ & $\begin{array}{c}\mathrm{D}(\mathrm{LHR}(-\mathrm{T})) \\
\gamma_{\mathrm{T}}\end{array}$ & $\begin{array}{c}\mathrm{D}(\mathrm{LTV}(-\mathrm{T})) \\
\delta_{\mathrm{T}}\end{array}$ \\
\hline $\mathbf{1}$ & 0.27 & -0.26 & $-0.77 * *$ & $0.55 *$ \\
\hline $\mathbf{2}$ & 0.21 & -0.14 & $-0.61 *$ & $0.53 *$ \\
\hline $\mathbf{3}$ & 0.24 & -0.17 & $-0.68 * *$ & 0.50 \\
\hline $\mathbf{4}$ & -0.08 & -0.26 & -0.42 & 0.15 \\
\hline $\mathbf{6}$ & 0.36 & -0.12 & $-0.66^{* *}$ & $0.63 *$ \\
\hline $\mathbf{7}$ & 0.18 & $-0.57 * *$ & -0.11 & -0.03 \\
\hline $\mathbf{8}$ & 0.39 & 0.04 & -0.55 & 0.16 \\
\hline & 0.23 & $-0.63 * *$ & -0.30 & 0.10 \\
\hline
\end{tabular}

The results of model regression are:

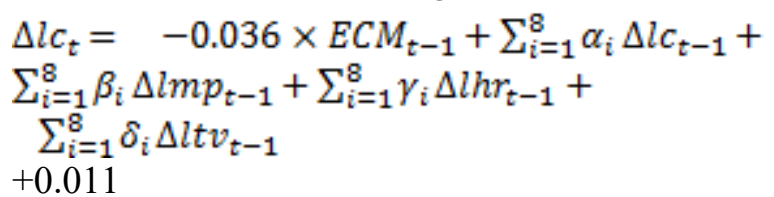

It can be seen from this error correction model that the fluctuation of $1 \mathrm{c}$ in the $\mathrm{t}$ period is caused by two parts: one is the direct influence of the lag term of $1 \mathrm{c}, 1 \mathrm{mp}$, lhr and ltv differential term on lc short-term fluctuation, and it can be seen that the hash The lagged term of the rate and volume has the most significant and biggest impact. Another is the adjustment of the long-run equilibrium relationship. The error correction coefficient of the equation is -0.036 , which indicates that the convergence mechanism of the long-term equilibrium trend deviation plays a role. When the transaction cost deviates from the long-term equilibrium due to the short-term fluctuation, the economic system will return the disequilibrium state to $3.6 \%$.

\section{Conclusion}

The transaction fee of bitcoin which is negatively related to computing force is positively correlated with price and transaction quantity. Besides, the price has the greatest influence on the transaction fee. In the long run, the impact of demand on transaction fee is greater than that of supply. The demand curve will shift to the right more than the supply curve to the right degree due to the limit of computing force. What's more, there will be a downward trend for bitcoin fees. 


\section{Acknowledgment}

F.A author expresses her gratitude to all those who have helped her during the writing of this paper, especially for her supervisor Lei Tian, who has offered her valuable suggestions, patient instruction, insightful criticism and expert guidance. She also owes a special debt of gratitude to all the researchers in the field of bitcoin, whose academic studies play an important role in the construction of the thesis .Finally, authors all deeply appreciate Beijing University of Posts and Telecommunications who offers such a great platform that they can devote themselves to academic studies of advancing subjects. This paper gets financial support from Research Innovation Fund for College Students of Beijing University of Posts and Telecommunications and Beijing Co-Construction Program.

\section{References}

[1] Nakamoto, S. Bitcoin: A Peer-to-Peer Electronic Cash System. Consulted, 2009.

[2] Coase, R.H. The nature of the firm. Economica, 1937.

[3] Commons, J.R (1931). "Institutional Economics". American Economic Review. 21: 648-657. Retrieved February 8, 2013.

[4] Williamson, Oliver E. The Economic Institutions of Capitalism. Firms, Markets, Relational Contracting. Social Science Electronic Publishing, 1985, 32(2):61-75.

[5] Hill, J. Transaction costs and liquidity in evolving markets. Superbowl of Indexing Conference, 2001, 2: 109-116.

[6] Kroll, J.A., Davey, I.C., Felten, E.W. The Economics of Bitcoin Mining, or Bitcoin in the Presence of Adversaries. Proceedings of weis, 2013.

[7] Houy, N. The Bitcoin Mining Game. Ssrn Electronic Journal, 2014.

[8] Fisher, I., Barber, W. J. The Purchasing Power of Money.Pickering \& Chatto, 1911. 